\title{
Management of Complications in 1452 Pediatric and Adult Cochlear Implantations
}

\author{
Original Investigation \\ Elvan Onan ${ }^{1}$ (D), Ülkü Tuncer ${ }^{2}$ (D), Sümbül Bayraktar ${ }^{1}$ (D), Mete Kıroğlu ${ }^{1}$ \\ ${ }^{1}$ Department of Otorhinolaryngology, Çukurova University School of Medicine, Adana, Turkey \\ ${ }^{2}$ Department of Otorhinolaryngology, Acıbadem University Acıbadem Adana Hospital, Adana, Turkey
}

Abstract

ORCID IDs of the authors: M.D. 0000-0002-1923-3731: Ö.T.0000-0002-0689-6632; ö.S. 0000-0001-5041-2802; S.0. 0000-0002-0125-1536; E. $0.0000-0003-1018-3464$ Ü.T. 0000-0001-8040-3114; S.B. 0000-0002-0228-9106; M.K. 0000-0002-4983-0406.

Cite this article as: Dağkıran M, Tarkan Ö, Sürmelioğlu Ö, Özdemir S, Onan E, Tuncer Ü, et al. Management of Complications in 1452 Pediatric and Adult Cochlear Implantations. Turk Arch Otorhinolaryngol 2020; 58(1): 16-23.

\section{Corresponding Author:}

Muhammed Dağkıran

muhammeddagkiran@gmail.com

Received Date: 19.12.2019

Accepted Date: 22.02 .2020

Content of this journal is licensed under a Creative Commons Attribution 4.0 International License. Available online at www.turkarchotolaryngol.net
Objective: The aim of this study was to determine the short- and long-term complications after cochlear implantation (CI) procedures and to discuss the management and prevention of these complications.

Methods: The study included a total of 1452 pediatric and adult cochlear implantation procedures performed in our clinic from March 2000 through September 2019. Of the 1452 implantations, 1201 were performed in children and 156 in adults. The minimum follow-up period was three months and maximum was 19 years. The mean age of the patients was $6.7 \pm 3.9$ years (range, 10 months -69 years) at the time of their respective procedures. Complications were classified as major complications requiring reimplantation, major complications not requiring reimplantation and minor complications. All postoperative complications and treatment methods were examined.
Results: A total of 148 (10.1\%) complications were observed in the 1452 cochlear implants. Of these, 69 $(4.75 \%)$ were major and $79(5.44 \%)$ were minor complications. While $40(2.75 \%)$ of the major complications required reimplantation, 29 (1.99\%) did not. The most common cause of major complications leading to reimplantation was device failure (29 patients, $1.99 \%)$. The most common cause of minor complications was hematoma (21 patients). Total complication rates $(6.68 \%)$ were significantly higher in children than in adults $(3.51 \%)(\mathrm{p}=0.00)$.

Conclusion: Our 19 years of clinical experience has shown that $\mathrm{CI}$ is a successful and safe procedure that can be performed with low major complication rates. It is important to know the possible complications and to manage them correctly.

Keywords: Cochlear implantation, complications, device failure, flap necrosis, meningitis

\section{Introduction}

Cochlear implantation (CI) is a safe surgical procedure, for more than 20 years, for the hearing rehabilitation of patients with severe sensorineural hearing loss. Given the increasing need for bilateral CIs, which in turn is leading to an increase in the number of $\mathrm{CI}$ procedures, it is very important to be aware of the possible CI complications and their treatment. CI complications can occur due to the surgical technique, foreign body implantation or device failure (1). While there are studies which classify the complications as early and late (2) or intraoperative and postoperative (3), most of the studies use the terms major and minor to define the com- plications. Minor complications can be treated with conservative methods, medical treatment and minimal surgical procedures, whereas major complications can be life-threatening conditions requiring prolonged hospitalization and/or surgical intervention (4).

In this study we present the results of our 19 years of experience in managing $\mathrm{CI}$ complications. We retrospectively reviewed the complications and their methods of management of 1452 CI cases in 1357 pediatric and adult patients. To the best of our knowledge, this is the study with the highest number of cases reported in the literature to date. 


\section{Methods}

\section{Patients}

Patients who received unilateral or sequential bilateral CI in the Department of Otorhinolaryngology, Çukurova University Hospital from march 2000 through september 2019 were included in this single-center retrospective study. A total of 1452 cochlear implants were placed in 650 (47.7\%) female and 707 (52.3\%) male patients of whom 1201 (86.1\%) were children and $156(13.9 \%)$ were adults. The ages of the patients ranged from 10 months to 69 years, with a mean operation age of $6.7 \pm 3.9$ years. Follow-up period was minimum three months and maximum 19 years. All patients were followed-up regularly. Ethics committee approval was obtained from the Local Ethics Committee of Çukurova University School of Medicine Non-Interventional Clinical Trials (136/10/060919).

\section{Surgical Procedure}

All patients were operated on by experienced surgeons. The procedures were performed alternatively by seven surgeons, five seniors and two juniors. Junior surgeons had an average experience of nine years and senior surgeons of 18 years in cochlear implant surgery. Routine surgical procedure was used in all patients. Round window or promontorium cochleostomy was performed to enable electrode insertion into the cochlea. After electrode insertion, auditory nerve response telemetry and/or neural response telemetry were performed. X-ray imaging was used to verify electrode alignment on the first postoperative day. Over the years, there have been some modifications to the surgical procedure. In earlier years, an extended retroauricular skin incision was made and the receiver of the implant was placed in the bony bed, and then fixed with sutures to both sides of the bony bed. As of 2009, however, a minimal retroauricular skin incision and a tight subperiosteal pocket method was used.

\section{Cochlear Implant Devices}

Six hundred and eighty-one Med-EL, 677 Nucleus, 73 Advanced Bionics and 21 Oticon cochlear implant devices were used (Med-EL devices were manufactured by Med-EL Corp., Innsbruck, Austria; Nucleus devices were manufactured by $\mathrm{Co}^{-}$ chlear Corp., Lane Cove, Australia; Clarion devices were manufactured by Advanced Bionics, Sylmar, CA, USA; Oticon devices were manufactured by Oticon Medical, Vallauris, France).

\section{Classification of Complications}

Complications were classified as major and minor. The conditions considered as minor complications were those requiring an outpatient medical treatment or a prolonged hospital stay (e.g., vertigo, minor wound infection, acute otitis media), spontaneous recovery or requiring simple medical treatment (e.g., transient facial paralysis, chorda tympani damage), or requiring minimal intervention or needle aspiration (hematoma or seroma).

Major complications were divided into two subgroups as those that required and those that did not require reimplantation. Major complications that did not require reimplantation were those where additional surgical intervention was needed (e.g., flap ne- crosis, hematoma, seroma cholesteatoma, tympanic membrane perforation, facial paralysis), that led to permanent loss of function (e.g., facial paralysis), or presented life-threatening severe clinical conditions (e.g., meningitis). Major complications that required reimplantation were device failure (e.g., hard failure, soft failure) or foreign body implantation (e.g., flap necrosis), or misplacement or displacement problems.

\section{Statistical Analysis}

Statistical analysis was performed using the IBM Statistical Package for Social Sciences for Windows version 20.0 (SPSS Corp.; Armonk, NY, USA). Percentages and frequencies were calculated for the descriptive statistics of the data. In comparisons by certain parameters, normality hypotheses were tested with the Kolmogorov-Smirnov, and the Shapiro-Wilks tests and the Chi-Square statistics and T-test for independent groups were used. In all analyses, $\mathrm{p}<0.05$ was considered statistically significant.

\section{Results}

A total of 148 (10.1\%) complications were observed in the 1452 CI devices placed in 1357 patients (Table 1). Sixty-nine (4.75\%) of these were major and 79 (5.44\%) were minor complications. Of these, $6.68 \%$ were seen in adults and $3.51 \%$ in children $(\mathrm{p}=0.00)$. Device failure was statistically higher in children than in adults $(\mathrm{p}<0.05)$. Major complications were significantly higher in children than in adults $(\mathrm{p}=0.00)$ (Table 1$)$. One hundred and ninety CIs were made through extended retroauricular skin incision and 1262 CIs through minimal retroauricular skin incision.

\section{Major Complications Requiring Reimplantation}

Forty major complications were observed to have required reimplantation (Table 1). A total of 29 (1.9\%) patients required reimplantation due to device failure. Three $(10.3 \%)$ of these $\mathrm{pa}^{-}$ tients were adults and $26(89.7 \%)$ were children $(\mathrm{p}=0.01)$.

Reimplantation was performed in four patients due to flap necrosis (Figure 1a, b). Of these four patients, extended retroauricular skin incision was used in three, and minimal retroauricular skin incision was used in one. Statistically, a wider incision was found to more commonly lead to flap necrosis $(p<0.05)$. All four patients had undergone scalp rotation flap surgery, after which necrosis reoccurred, the devices were explanted and reimplantation surgery was performed in the contralateral ear. There were no complications in the other ears in the follow-up period.

Three patients underwent reimplantation due to perioperative misplacement. The diagnosis of misplacement in these patients was achieved by postoperative computed tomography (CT). CT was performed due to intraoperative impaired neural response telemetry test in two of them and severe postoperative vertigo in one. In CT images, the electrode was found in the superior semicircular canal in one patient (Figure 2a), in the hypotympanic air cells in the second patient (Figure 2b), and in the Hytrl's fissure in the third patient (Figure 2c). Hyrtl's fissure (also known as tympanomeningeal fissure) is a transient anatomic landmark in the developing 
Table 1. Major and minor cochlear implantation complications and their distribution among pediatric and adult patients

\begin{tabular}{|c|c|c|c|c|}
\hline Major complications requiring reimplantation & Total & Pediatric & Adult & $\mathrm{p}$ \\
\hline Device failure & 29 & 26 & 3 & 0.01 \\
\hline Flap necrosis & 4 & 3 & 1 & $>0.05$ \\
\hline Misplacement & 3 & 2 & 1 & $>0.05$ \\
\hline Displacement & 2 & 2 & 0 & $>0.05$ \\
\hline Cholesteatoma & 1 & 1 & 0 & $>0.05$ \\
\hline Meningitis & 1 & 1 & 0 & $>0.05$ \\
\hline Subtotal (n) (\%) & $40(2.75)$ & $35(2.4)$ & $5(0.3)$ & 0.00 \\
\hline \multicolumn{5}{|l|}{ Major complications not requiring reimplantation } \\
\hline Wound infection & 3 & 2 & 1 & $>0.05$ \\
\hline Flap necrosis & 2 & 1 & 1 & $>0.05$ \\
\hline Meningitis & 4 & 4 & 1 & $>0.05$ \\
\hline Migration of magnet & 3 & 3 & 0 & $>0.05$ \\
\hline Electrode migration & 2 & 2 & 0 & $>0.05$ \\
\hline Major hematoma & 7 & 5 & 2 & $>0.05$ \\
\hline Facial nerve paralysis & 2 & 1 & 1 & $>0.05$ \\
\hline Cholesteatoma & 2 & 1 & 1 & $>0.05$ \\
\hline Tympanic membrane perforation & 4 & 1 & 3 & $>0.05$ \\
\hline Subtotal (n) (\%) & $29(1.99)$ & $19(1.3)$ & $10(0.6)$ & $>0.05$ \\
\hline \multicolumn{5}{|l|}{ Major complications } \\
\hline Subtotal (n) (\%) & $69(4.75)$ & $54(3.71)$ & $15(1.03)$ & 0.00 \\
\hline \multicolumn{5}{|l|}{ Minor complications } \\
\hline Minor hematoma/Seroma & 21 & 15 & 6 & $>0.05$ \\
\hline Transient vertigo & 16 & 2 & 14 & $>0.05$ \\
\hline Chorda tympani dysfunction & 15 & 4 & 11 & $>0.05$ \\
\hline Acute otitis media & 12 & 11 & 1 & $>0.05$ \\
\hline Minor wound infection & 7 & 4 & 3 & $>0.05$ \\
\hline Temporary facial nerve weakness & 3 & 2 & 1 & $>0.05$ \\
\hline Skin lesion in contralateral ear & 3 & 3 & 0 & $>0.05$ \\
\hline Facial stimulation & 2 & 2 & 0 & $>0.05$ \\
\hline Minor complications subtotal (n) (\%) & $79(5.44)$ & $43(2.96)$ & $36(2.47)$ & $>0.05$ \\
\hline Total (n) (\%) & $148(10.19)$ & $97(6.68)$ & $51(3.51)$ & 0.00 \\
\hline
\end{tabular}

fetal petrous temporal bone. Successful reimplantation was performed in all patients. In two pediatric CIs, the electrode was displaced after the receiver of the cochlear implant migrated to the occipital area in the subperiosteal plane in the early postoperative period (Figure 3 ). Successful reimplantation was performed in both of these patients.

One pediatric patient underwent reimplantation due to cholesteatoma. The patient was admitted to our clinic with purulent otorrhea in the $5^{\text {th }}$ postoperative year. Otoscopic examination and CT scan showed an image consistent with cholesteatoma in the middle ear. Exploration was planned. The electrode was removed to completely clean the cholesteatoma, the implant was explanted and reimplantation was performed in the same ear. We had one pediatric patient who required reimplantation due to recurrent meningitis. After the third attack, reimplantation was performed with a new custom made device (form electrode series of Med-EL device), which was designed for better control of the cerebrospinal fluid leakage.

\section{Major Complications not Requiring Reimplantation}

Twenty nine (1.99\%) of the major complications did not require a reimplantation procedure (Table 1 ). Wound infection was observed in three patients. These patients were re-operated on and explored. Abscess drainage, debridement and irrigation with saline were performed and intravenous ceftriaxone was given at $50 \mathrm{mg} / \mathrm{kg} /$ day. Infection was cured in all three patients after this treatment.

Debridement and rotation scalp flap procedures were performed in two patients with flap necrosis. One was an adult patient in whom success was achieved. The other was a pediatric patient in whom flap necrosis recurred five weeks later. The CI was ex- 

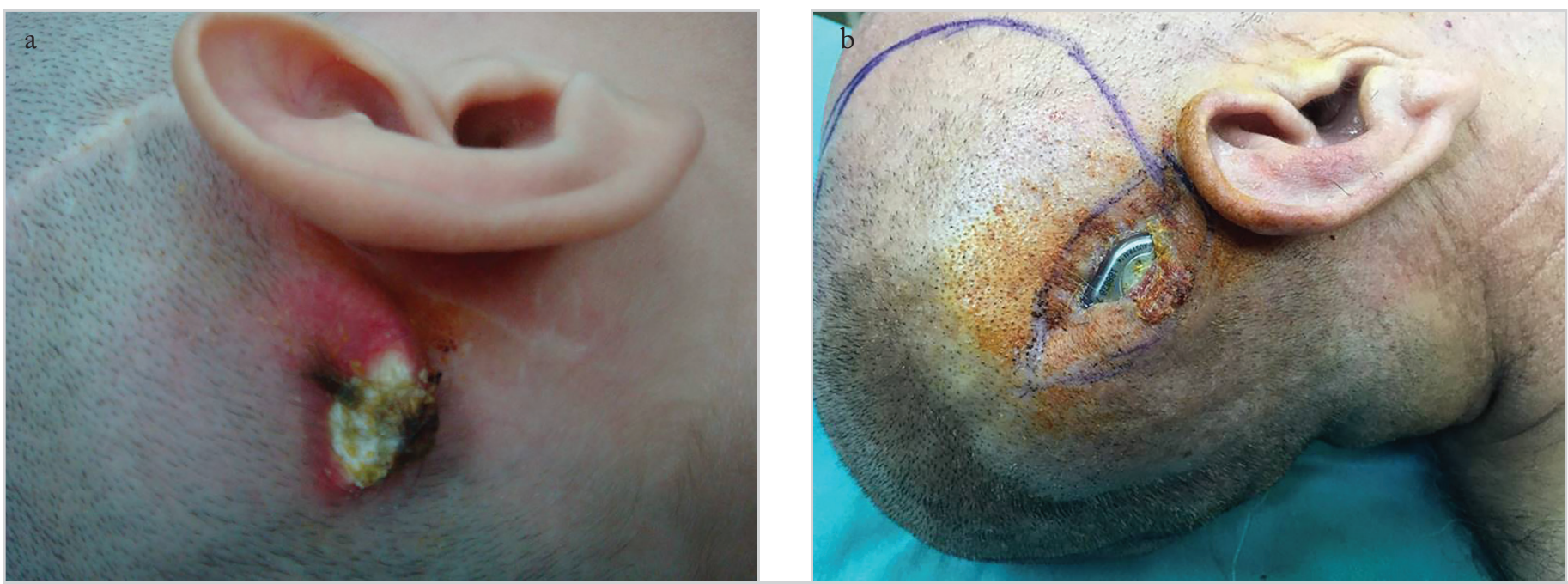

Figure 1.a.b. Flap necrosis in a pediatric patient (a). Flap necrosis in an adult patient (b)
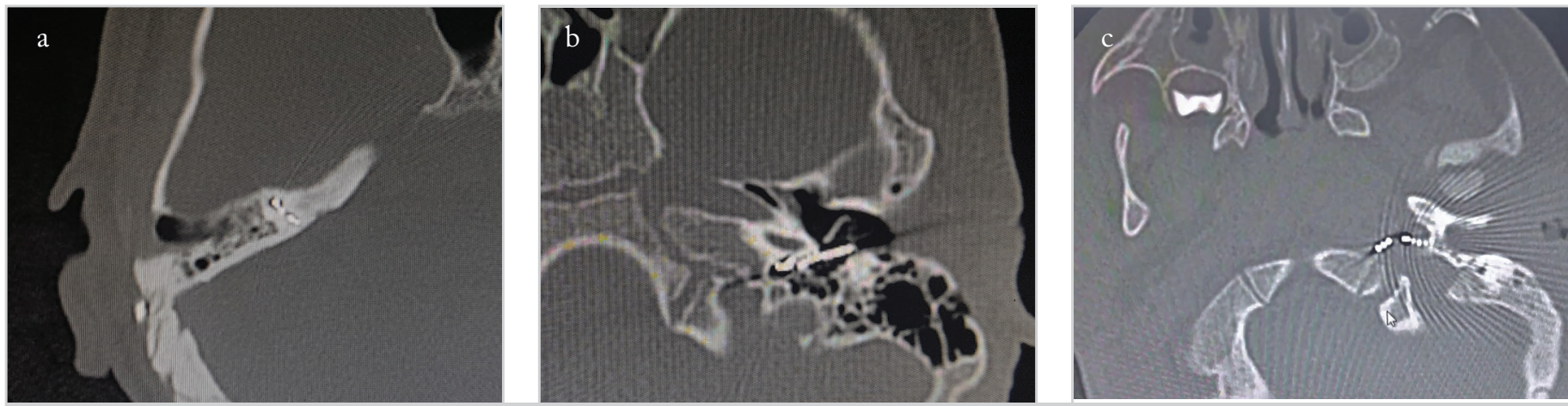

Figure 2. a-c. Electrode misplacement to the superior semicircular canal (a). Electrode misplacement to the hypotympanum (b). Electrode misplacement to Hytrl's fissure (c)

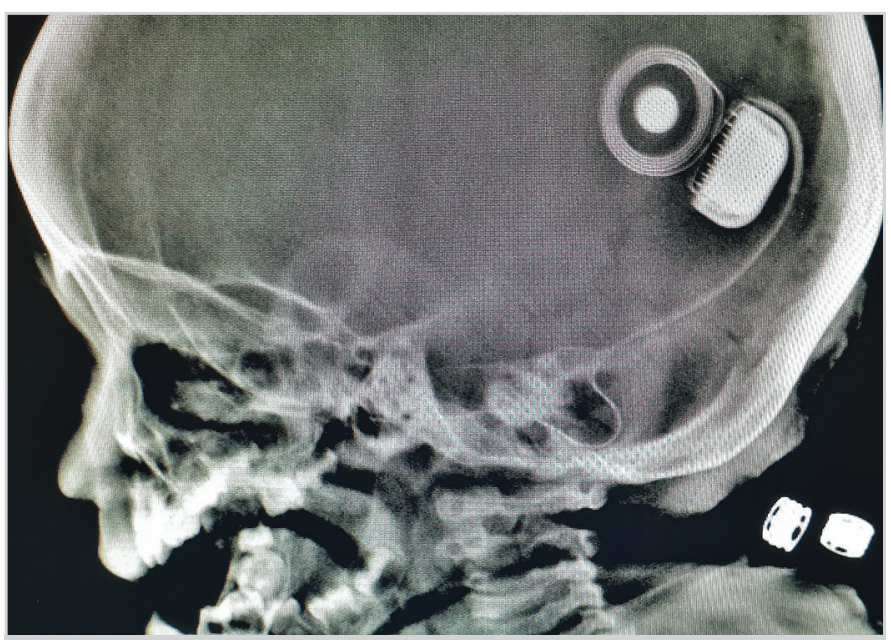

Figure 3. In the lateral Stenver's x-ray imaging of this pediatric patient, the electrode was displaced out of the cochlea due to receiver migration to the occipital area

planted, and a contralateral ear reimplantation was offered but the family refused.

Four pediatric patients developed meningitis in the postoperative period. Three of them had cerebrospinal fluid rhinorrhea. All patients also had cochlear anomaly and developed intraoperative gusher. Three patients were re-operated on and round window sealing were performed with facias and fibrin glue without removing the cochlear implant. Lumbar drainage was also performed in these patients. Postoperative $100 \mathrm{mg} / \mathrm{kg} / \mathrm{day}$ ceftriaxone and 60 $\mathrm{mg} / \mathrm{kg} /$ day vancomycin were administered. One of four patients had no rhinorrhea, and complete recovery was achieved with intravenous antibiotic therapy without revision surgery.

Magnet migration was observed in three patients, all were children and had a history of trauma. Examinations and CT imaging of these patients revealed that the magnets were not in place and surgical exploration were planned. Flap elevation was performed over a 3-4 $\mathrm{cm}$ skin incision posterior to the cochlear implant. The magnet was found to have been displaced, hence reposed without removing the cochlear implant.

Electrode migration was observed in two pediatric patients. One patient was observed to show an abnormal hearing performance one month after the operation. The other patient presented with deterioration in auditory results in the first postoperative year. CT imaging of these patients revealed that some parts of the electrode had shifted from the round window to the middle ear. In both patients, full insertion was achieved by revision surgery without reimplantation.

Major hematoma developed in seven cases. The surgical field was explored in these patients. Possible bleeding areas were 
identified and bleeding control was achieved. Drain was inserted, followed by pressure dressing. Hematoma did not recur in these patients.

In two cases, House-Brackmann Grade 6 facial paralysis developed immediately after the surgery. These patients were immediately operated on and limited facial decompression was performed. The facial nerve was intact but slightly edematous. During follow-up, the two patients showed almost complete improvement (grade 2) in one year.

Two patients developed cholesteatoma in the fourth and sixth years. These patients presented with minimal perforation in the pars tensa and the purulent otorrhea. Re-exploration was performed on both patients. One patient had cholesteatoma in the middle ear and the mesotympanum, while the other patient had cholesteatoma in the hypotympanum. Both were removed microscopically and over-underlay tympanoplasty was performed with tragal cartilage and perichondrium. The surgeries were completed without removing the implant. The operation note indicated that these two patients had developed annulus damage during the $\mathrm{CI}$ procedure.

In four cases tympanic membrane perforation occurred postoperatively in the $1^{\text {st }}, 3^{\text {rd }}, 9^{\text {th }}$ and $15^{\text {th }}$ months, respectively. All patients underwent endoscopic over-underlay tympanoplasty using tragal cartilage perichondrium and by preserving the implant electrode. Reperforation was not observed in the follow-up of the patients.

\section{Minor Complications}

Seventy-nine minor complications were observed (Table 1). Minor hematoma/seroma developed in $21 \mathrm{CIs}$. Hematoma/seroma of the patients regressed with needle aspiration and/or pressure dressing. No additional surgery was performed. Transient vertigo was observed in the early postoperative period in 16 patients (14 adults, 2 children). Nystagmus was seen in three patients and disappeared within the first three days. The vertigo of all patients improved significantly within three days to six months. Fifteen patients (four children, 11 adults) developed transient chorda tympani damage. These 15 patients were thought to have chorda

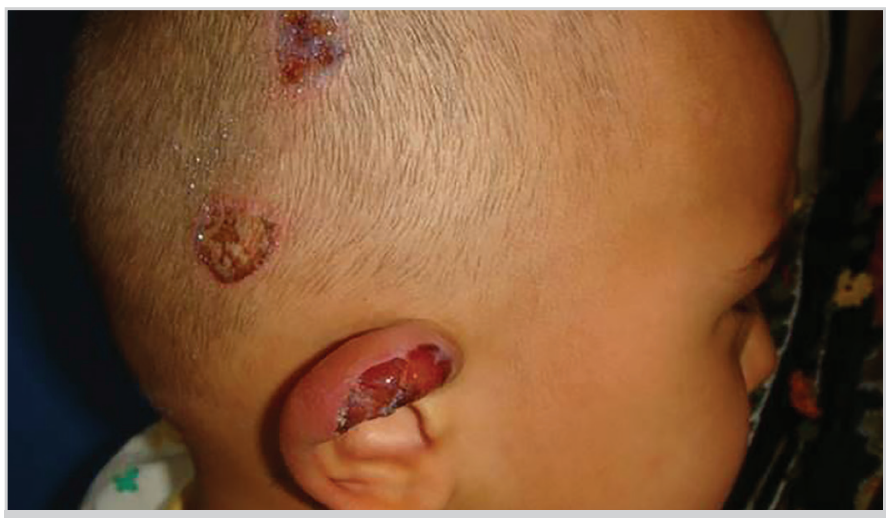

Figure 4. Bullous lesion due to pressure during surgery in the contralateral ear of a patient tympani damage considering their complaints in taste sensation. No treatments were given to the patients and complaints of taste disorder regressed in the first 3-6 months. In 12 patients, acute otitis media developed between the fifth postoperative day and the third year. All 12 patients received antibiotherapy only. None of the patients required ventilation tubes during follow-up. Seven minor wound infections developed. All patients recovered within two weeks with antibiotherapy.

Transient facial paralysis developed in three patients. All three patients had House-Brackmann grade 3 facial paralysis. They were treated with intravenous corticosteroid and facial paralysis completely recovered within 10 days postoperatively. In these patients, we thought the facial nerve damage was occurred due to thermal effect of drill. In three patients, lesions developed due to pressure in the contralateral ear. Two patients had bullous appearance and one patient had ecchymotic appearance (Figure 4). This complication was thought to be associated with the pressure during their prolonged operations. The lesions regressed with topical antibiotic treatment. Facial stimulation was observed in two cases at postoperative 1st and 15th months. These patients showed improvement with the reprogramming of the cochlear implant and with electrode deactivation without additional surgery.

\section{Discussion}

The rate of major complications in 1452 cochlear implantations in 19 years was $4.75 \%$ (69 patients) and the rate of minor complications was 5.4\% (79 patients). The overall complication rate was $10.1 \%$ (148 patients). These rates were not found to contradict those reported in the literature. As a matter of fact, the complication rates given in the literature range from $2 \%$ to $62.5 \%(5-10)$. We believe that this wide range may be due to the differences in the classification of complications, the available surgical techniques at the time of operation, and differences in the lengths of the follow-up periods. Theunisse et al. (11) reported that the decision of whether or not a chorda tympani injury and a device failure are considered as medical complications affected the complication rates. In another study Theunisse et al. (12) also reported that minor complication rates differ more among publications and their classification is not clear.

In our study, the most common major complication was device failure (29 patients, 1.99\%) and found consistent with the literature. Some authors classify device failure as a complication associated with the device $(3,13)$. If this classification was accepted in our study, our major complication rate would decrease from $4.75 \%$ to $2.7 \%$. Therefore, whether or not device failures are included in the analysis of major complications is a major aspect. In our study, most of the device failures were secondary to trauma and higher in the pediatric age group $(p<0.05)$. Parents of children undergoing CI should be warned for maximum protection of their children from head trauma.

In this study, after device failure, flap necrosis was the second most common cause of reimplantation seen in six $(0.41 \%) \mathrm{pa}^{-}$ 
tients. In the literature, the rate of flap necrosis in CI patients is reported as $0.24-3.8 \%(14-16)$. Of the six patients with flap necrosis, four required reimplantation. A statistically significant lower flap necrosis was observed after 2009 when we started using minimal retroauricular incision $(\mathrm{p}<0.05)$. In a similar study, flap infection was found to be statistically significant in $10(3.92 \%)$ patients with extended postauricular incision and in two $(0.6 \%)$ patients with minimal approach (17). Therefore, it is important to follow the course of the vascular feeding of the flap when performing the flap incision. Staphylococcus aureus and Pseudomonas aeruginosa are the most common agents in flap infection (1). Pseudomonas aeruginosa can cause biofilm reactions, hence require reimplantation by colonizing around the implant, are unresponsive to antibiotics and can lead to flap necrosis (7).

The most common major complication which does not require reimplantation was hematoma, seen in 28 patients (1.92\%). Hematoma drainage was performed in seven patients, in the operating room, with an incision to the posterior of the implant, followed by drain application for 2-3 days. Therefore, these situations were considered as major complications. Needle aspiration and pressure dressing were sufficient to control hematoma in 21 patients, thus considered as minor complications. Hematoma was the most common minor complication. The rate of hematoma after cochlear implantation is given as $0.4-5.8 \%$ in the literature $(7,18,19)$. Incision type, coagulopathy and trauma are the predisposing factors for hematoma. In case of suspected hematoma, ultrasound examination, needle aspiration and tight dressing can be performed. If the hemato$\mathrm{ma}$ is resistant or advanced, the patient should be taken to the operating room and explored, hematoma should be drained to achieve bleeding control.

In this study, three patients received reimplantation for misplacement and two for displacement. None of these patients had cochlear abnormality. Intraoperative electrophysiological tests and radiological imaging are useful to avoid misplacement and displacement, but they should not be considered as certain methods (20). Misplacement sites reported in the literature are internal acoustic canal, superior semicircular canal, Eustachian tube, internal carotid artery, petrous apex and hypotympanic air cells (21-23). Surgical landmarks should be well known to prevent misplacement, as late recognition may lead to a decline in the patient's auditory performance. If there is any suspicion that the electrode is not in the cochlea, or in cases that do not benefit from the implant in the postoperative period or have limited benefit, CT imaging should be performed without delay to explore the presence of misplacement.

The misplacement was determined in two patients. In the first patient the implant processor was migrated to the vertex and to the occipital region in the second, so the electrodes had slipped out of the cochlea in these patients. CT imaging should also be performed in cases of suspected displacement. In order to avoid this situation as much as possible, the subperiosteal pocket should be created up to the width of the implant and over elevation of the periosteum should be avoided.
Meningitis developed in five (0.34\%) cases and all of them were patients with cochlear anomaly. Medical treatment was sufficient in only one patient; in the remaining four, re-exploration was done and re-implantation was performed in only one patient. Biofilm reaction should be kept in mind in patients resistant to medical or surgical treatment and the device should be removed and reimplanted if necessary. Especially patients with cochlear anomaly are at high risk for meningitis after CI. Daneshi et al. (24) found that the complication rate of meningitis after a CI before the vaccination period was $4 \%$, compared to $0.1 \%$ after vaccination. Since 2007 , systemic meningitis vaccines are routinely administered in our clinic.

In the literature, cholesteatoma was observed in around $1 \%$ of patients after $\mathrm{CI}$ (18). In our study, cholesteatoma was very rare and it was seen in three $(0.2 \%)$ patients. Only one of them required reimplantation. In the other two the cholesteatoma was removed without reimplantation. According to the data obtained from the surgical records, these three patients had annulus damage during the first operation. It is important to avoid tympanic annulus damage, excessive thinning and/or damage of the posterior wall, which must be repaired appropriately with fascia, bone or cartilage in case of occurrence.

The most common minor complication after hematoma was transient vertigo in our study. Transient vertigo was observed in 16 patients $(1.1 \%)$. In the literature, this rate ranges from $9.5 \%$ to $49 \%(25-27)$. This low vertigo incidence compared to those reported in the literature may be attributed to the fact that most of our patients were in the pediatric age group and the majority of them were in the prelingual stage, therefore could not express the symptoms of vertigo. In our previous study, we demonstrated that early vestibular dysfunction and vertigo symptoms after CI tend to improve rapidly over time and persistent vertigo was not observed in any case (25). There are studies suggesting that round window cochleostomy protects vestibular functions better than promontorium cochleostomy (28). In our clinic, electrode insertion through the round window was preferred in every possible case.

Chorda tympani dysfunction was observed in $15(1.03 \%) \mathrm{pa}^{-}$ tients in our study. This rate was determined based on patient accounts. We think that this ratio might actually be higher as pediatric patients have difficulty in expressing the taste disorder. In different studies, taste dysfunction varies between 5-25\% (29). If drilling is made extremely close to the external auditory canal to avoid fascial nerve injury, this may result in chorda tympani damage either directly or with the thermal effect of the drill. During posterior tympanotomy, irrigation with abundant water can decrease the rate of dysfunction of the chorda tympani.

AOM was observed in $12(0.8 \%)$ patients. All except one were pediatric patients. Medical treatment was sufficient in all of these patients and none of them developed meningitis. Since the risk of contamination by cochleostomy increases, children 
undergoing CI have an increased risk of meningitis compared to children with normal hearing, especially in the first month (1).

In our study, the rate of facial nerve paralysis was $0.34 \%$ (five patients), compared to $0.7 \%$ reported in the literature (30). Three of them (0.2\%) had House-Brackmann Grade 3 fascial paralysis and improved with steroid treatment, the other two $(0.13 \%)$ had House-Brackmann grade 6 and fascial nerve decompression was performed. Both of the latter patients had almost complete improvement within one year. The risk of facial nerve injury increases especially in patients with internal ear anomalies due to atypical anatomical variations. Most facial paralysis improve spontaneously or with steroid therapy, but cable grafts may be used in cases that do not improve or have direct nerve damage during operation (24). Facial nerve monitors are routinely used in all cases in our clinic to prevent facial nerve damage. Temporary facial stimulation is another complication related to facial nerve other than facial paralysis. In our study, only two $(0.13 \%)$ patients were reported. This problem was solved by reprogramming the CI without any surgery.

Although it is not mentioned in many studies, in our study we had three $(0.2 \%)$ pediatric patients with skin lesions in the contralateral ear. The risk increases especially in those with thin skin and prolonged operation time. To prevent this complication, care should be taken to position the head with a 30-degree angle between the operating table and the sagittal plane of the head and to avoid ear bending (7).

\section{Conclusion}

Our study, which reflects the results of almost 20 years of our experience in $\mathrm{CI}$, showed that $\mathrm{CI}$ is a very successful and safe surgery with limited number of serious complications. Knowing all possible complications of $\mathrm{CI}$ and taking these into consideration both during the surgery and the long-term follow-up can minimize the risks of this procedure.

Ethics Committee Approval: Ethics committee approval was obtained for this study from the Non-Interventional Clinical Trials Local Ethics Committee of Çukurova University School of Medicine (136/10/060919).

Informed Consent: Informed consent was not received due to the retrospective nature of the study.

Peer-review: Externally peer-reviewed.

Author Contributions: Concept - M.D., Ö.T., Ö.S.; Design - M.D., Ö.T., Ü.T.; Supervision - M.D., M.K, Ü.T.; Fundings - M.D., S.Ö., Ü.T.; Materials - M.D., Ö.T., Ü.T.; Data Collection and/or Processing - M.D., E.O., S.B.; Analysis and/or Interpretation - M.D., E.O., S.B., S.Ö.; Writing - M.D., Ö.T., E.O.; Critical Reviews - M.D., Ü.T., Ö.T., Ö.S., M.K.

Conflict of Interest: The authors have no conflicts of interest to declare.

Financial Disclosure: The authors declared that this study has received no financial support.

\section{References}

1. Farinetti A, Ben Gharbia D, Mancini J, Roman S, Nicollas R, Triglia JM. Cochlear implant complications in 403 patients: Comparative study of adults and children and review of the literature. Eur Ann Otorhinolaryngol Head Neck Dis 2014; 131: 177-82. [Crossref]

2. Kempf HG, Stöver T, Lenarz T. Mastoiditis and acute otitis media in children with cochlear implants: Recommendations for medical management. Ann Otol Rhinol Laryngol Suppl 2000; 185: 25-7. [Crossref]

3. Venail F, Sicard M, Piron JP, Levi A, Artieres F, Uziel A, et al. Reliability and complications of 500 consecutive cochlear implantations. Arch Otolaryngol Head Neck Surg 2008; 134: 1276-8. [Crossref]

4. Cohen NL, Hoffman RA. Complications of cochlear implant surgery in adults and children. Ann Otol Rhinol Laryngol 1991; 100: 708-11. [Crossref]

5. Jiang Y, Gu P, Li B, Gao X, Sun B, Song Y, et al. Analysis and management of complications in a cohort of 1,065 minimally invasive cochlear implantations. Otol Neurotol 2017; 38: 347-51. [Crossref]

6. Coté M, Ferron P, Bergeron F, Bussières R. Cochlear reimplantation: Causes of failure, outcomes, and audiologic performance. Laryngoscope 2007; 117: 1225-35. [Crossref]

7. Tarkan Ö, Tuncer Ü, Özdemir S, Sürmelioğlu Ö, Çetik F, Kıroğlu M, et al. Surgical and medical management for complications in 475 consecutive pediatric cochlear implantations. Int J Pediatr Otorhinolaryngol 2013; 77: 473-9. [Crossref]

8. Olgun Y, Bayrak AF, Catli T, Ceylan ME, Aydin R, Duzenli U, et al. Pediatric cochlear implant revision surgery and reimplantation: An analysis of 957 cases. Int J Pediatr Otorhinolaryngol 2014; 78: 1642-7. [Crossref]

9. Hansen S, Anthonsen K, Stangerup SE, Jensen JH, Thomsen J, Cayé-Thomasen P. Unexpected findings and surgical complications in 505 consecutive cochlear implantations: A proposal for reporting consensus. Acta Otolaryngol 2010; 130: 540-9. [Crossref]

10. Jeppesen J, Faber CE. Surgical complications following cochlear implantation in adults based on a proposed reporting consensus. Acta Otolaryngol 2013; 133: 1012-21. [Crossref]

11. Theunisse HJ, Mulder JJ, Pennings RJE, Kunst HPM, Mylanus EAM. A database system for the registration of complications and failures in cochlear implant surgery applied to over 1000 implantations performed in Nijmegen, The Netherlands. J Laryngol Otol 2014; 128: 952-7. [Crossref]

12. Theunisse HJ, Pennings RJE, Kunst HPM, Mulder JJ, Mylanus EAM. Risk factors for complications in cochlear implant surgery. Eur Arch Otorhinolaryngol 2018; 275: 895-903. [Crossref]

13. Brito R, Monteiro TA, Leal AF, Tsuji RK, Pinna MH, Bento RF. Surgical complications in 550 consecutive cochlear implantation. Braz J Otorhinolaryngol 2012; 78: 80-5. [Crossref]

14. Qiu J, Chen Y, Tan P, Chen J, Han Y, Gao L, et al. Complications and clinical analysis of 416 consecutive cochlear implantations. Int J Pediatr Otorhinolaryngol 2011; 75: 1143-6. [Crossref]

15. Halawani R, Aldhafeeri A, Alajlan S, Alzhrani F. Complications of post-cochlear implantation in 1027 adults and children. Ann Saudi Med 2019; 39: 77-81. [Crossref]

16. Ikeya J, Kawano A, Nishiyama N, Kawaguchi S, Hagiwara A, Suzuki M. Long-term complications after cochlear implantation. Auris Nasus Larynx 2013; 40: 525-9. [Crossref]

17. Hwang CF, Ko HC, Tsou YT, Chan KC, Fang HY, Wu CM. Comparisons of auditory performance and speech intelligibility after cochlear implant reimplantation in Mandarin-speaking users. Biomed Res Int 2016; 2016: 8962180. [Crossref] 
18. Bhatia K, Gibbin KP, Nikolopoulos TP, O'Donoghue GM. Surgical complications and their management in a series of 300 consecutive pediatric cochlear implantations. Otol Neurotol 2004; 25 : 730-9. [Crossref]

19. Ovesen T, Johansen LV. Post-operative problems and complications in 313 consecutive cochlear implantations. J Laryngol Otol 2009; 123: 492-6. [Crossref]

20. Ying YL, Lin JW, Oghalai JS, Williamson RA. Cochlear implant electrode misplacement: Incidence, evaluation, and management. Laryngoscope 2013; 123: 757-66. [Crossref]

21. Mouzali A, Ouennoughi K, Haraoubia MS, Zemirli O, Triglia JM. Cochlear implant electrode array misplaced in Hyrtl's fissure. Int J Pediatr Otorhinolaryngol 2011; 75: 1459-62. [Crossref]

22. Mehanna AM, Gamaleldin OA, Fathalla MF. The misplaced cochlear implant electrode array. Int J Pediatr Otorhinolaryngol 2019; 117: 96-104. [Crossref]

23. Sun JQ, Sun JW, Hou XY, Bie YZ, Chen JW. Electrode array misplacement into the superior semicircular canal: As a rare complication of cochlear implantation. Int J Pediatr Otorhinolaryngol 2014; 78: 1537-40. [Crossref]

24. Daneshi A, Ajalloueyan M, Ghasemi MM, Hashemi BS, Emamjome H, Farhadi M, et al. Complications in a series of 4400 paediatric cochlear implantation. Int J Pediatr Otorhinolaryngol 2015; 79: 1401-3. [Crossref]
25. Dagkiran M, Tuncer U, Surmelioglu O, Tarkan O, Ozdemir S, Cetik F, et al. How does cochlear implantation affect five vestibular end-organ functions and dizziness? Auris Nasus Larynx 2019; 46: 178-85. [Crossref]

26. Melvin TA, Della Santina CC, Carey JP, Migliaccio AA. The effects of cochlear implantation on vestibular function. Otol Neurotol 2009; 30: 87-94. [Crossref]

27. Krause E, Louza JP, Hempel JM, Wechtenbruch J, Rader T, Gurkov R. Effect of cochlear implantation on horizontal semicircular canal function. Eur Arch Otorhinolaryngol 2009; 266: 8117. [Crossref]

28. Todt I, Basta D, Ernst A. Does the surgical approach in cochlear implantation influence the occurrence of postoperative vertigo? Otolaryngol Head Neck Surg 2008; 138: 8-12. [Crossref]

29. Alzhrani F, Lenarz T, TeschnerM. Taste sensation following cochlear implantation surgery. Cochlear Implants Int 2013; 14: 2006. [Crossref]

30. Lescanne E, Al Zahrani M, Bakhos D, Robier A, Morinière S. Revision surgeries and medical interventions in young cochlear implant recipients. Int J Pediatr Otorhinolaryngol 2011; 10: 12214. [Crossref] 